\title{
Making your case to the mental health review tribunal in England and Wales
}

The function of the mental health review tribunal is defined in Part $V$ of the Mental Health Act 1983. Together with statute and Common Law, it provides safeguards to those detained under the Act. The provisions of the Human Rights Act 1998 have strengthened these safeguards. The key articles in Schedule 1 of the Human Rights Act are $5(1)(\mathrm{e})$, relating to the lawful detention of persons of unsound mind; 5(4), providing that the lawfulness of such detention shall be decided speedily by a court; 6 , providing for a fair and public hearing within a reasonable time by an independent and impartial tribunal established by law; and 8, establishing the right to respect for a private and family life. The latter is relevant to disclosure, nearest relatives' rights, and treatment.

The tribunal is comprised of a president (a legal member of at least 7 years' experience, for restricted cases this will be a judge), a medical member and a member with experience of social services or administration.

\section{Responsible medical officer's report}

The Mental Health Tribunal Rules 1983 (Schedule 1, Part B) (SI 1983/942) require an 'up-to-date medical report, prepared for the tribunal, including the relevant medical history and a full report on the patient's mental condition'. Guidance on this is available from the tribunal office. The more comprehensive and up-to-date the medical report, the easier the job of the tribunal medical member, as there should be little additional information that he or she needs to disclose from their preliminary assessment.

The essential core of the medical report is the criteria for detention, as defined in Section 72 or 73 of the Act, as amended by the Mental Health Act (Remedial) Order 2001. If you have clearly addressed these and given reasons to support the assertions in your report, then the tribunal's task should be easier and the hearing shorter.

Do not avoid areas of difficulty or points that weigh in the patient's favour. These are likely to emerge anyway, and you may miss the opportunity to argue why, nevertheless, you believe that the patient should be detained.

\section{Care plan}

Your report should be accompanied by an up-to-date community care plan. You may think that there cannot be any realistic care plan to support the patient in the community. Nevertheless, you should prepare a provisional care plan. This may, indeed, help to make it clear to the tribunal how unrealistic a prospect discharge is. In any case, you should prepare a provisional care plan to support the patient in the event the tribunal decides to discharge.

Occasionally, responsible medical officers (RMOs) can be reluctant to discharge a patient, although they know that detention is no longer justified. They may feel, by leaving it to the tribunal, that the tribunal will take responsibility for the patient's discharge. You should not take this approach. If you believe the patient's detention is no longer justified the patient cannot be lawfully detained, and should be discharged.

\section{Tribunal proceedings}

\section{Fairness, formality and informality}

The tribunal routinely convenes half an hour before the anticipated start of the hearing, to read reports, hear the medical member's findings from the preliminary examination and discuss procedural issues. Delays are frequent because of (for example) lack of availability of reports or witnesses, or because the solicitor needs more time with the patient. The tribunal may require an adjournment to obtain additional evidence. Such delays are frustrating, but are unfortunately a common feature of a fair legal process.

The tribunal functions as a court and must comply with rules of law. Not to do so would risk a legal appeal against its decisions. Nevertheless, the tribunal will try to put the patient and witnesses at ease and to make the proceedings as informal as possible. Although hearings normally follow a standard pattern, the tribunal can hear submissions to take witnesses in a different order. The solicitor always has the opportunity to speak last.

\section{Disclosure and non-disclosure}

The medical member's role is unusual, taking an equal part with other tribunal members in the decision, while also providing evidence from a preliminary examination of the patient. Judge Stanley Burnton decided in the case of $R$ (on the application of S) [2002] that this is 'not incompatible with the requirements of Article 5' (of the Human Rights Act) provided that tribunals 'make absolutely sure that any significant findings by the medical member and any factual differences between what the RMO says and what the medical member has found, are laid open for the patient's representative to explore . . . at the start of the Tribunal hearing'. This laying open is called disclosure. 'The medical member must not form a concluded opinion until the conclusion of the hearing.' 'The other members are aware that it is only a provisional opinion . . . that 
they are free to disagree with it if the evidence and submissions before them lead them to a different conclusion.'

Under Rule 6, the responsible medical officer may submit a separate statement and request it is not disclosed to the patient on the ground that 'disclosure' would adversely affect the health or welfare of the patient or others. Under Rule 12, the tribunal must disclose this information to the patient's solicitor. You will have to explain to the tribunal, in the presence of the solicitor, why the statement should not be disclosed to the patient. Having heard the argument, the tribunal will decide if the statement should be disclosed, and may decide to disclose it. Even if the tribunal decides against disclosure, the solicitor may challenge the points made.

The tribunal is required to give clear reasons if it decides not to disclose evidence to the patient.

\section{The burden of proof}

Sections 72 and 73 of the Mental Health Act 1983 defined the criteria used by the tribunal in reaching its decision. Formerly, the tribunal had to discharge the patient if satisfied that the criteria for detention were not met. This meant, in effect, that in order to be discharged, the patient had to show that the criteria were not met. In the case of $R$ (on the application of $H$ ) [2001] this was held to be incompatible with human rights law. The Secretary of State, therefore, introduced the Mental Health Act 1983 (Remedial) Order 2001 (SI 2001/3712), amending sections 72 and 73 to the effect that unless the tribunal finds the criteria for detention are met it must discharge the patient. This is said to have shifted the burden of proof from the patient to the responsible authority. However, this is a simplification. The tribunal is inquisitorial and can take account of all the evidence before it. It should, nevertheless, be recognised that if the responsible authority does not place evidence before the tribunal then the patient may be discharged for lack of evidence.

In the same way that the patient is a party to the proceedings, so is the responsible authority (the hospital or trust). Consequently, the authority or its representative can make submissions and ask questions of witnesses at the hearing. Although it had generally been accepted that the responsible medical officer represented the detaining authority in the hearing, the judgment in $R$ (on the application of Mersey Health Care NHS Trust) [2003] makes it necessary to establish, at the outset, that the responsible medical officer represents the authority. If the president of the tribunal does not ask you about this you should make your position clear. This ensures you can try to put matters right by asking questions of the patient or other witnesses if you think there could be a danger of the tribunal reaching the wrong conclusion.

\section{Questions to the RMO}

The responsible medical officer's evidence is normally heard first. The president of the tribunal or the medical member will take you through your opinion as to whether the statutory criteria for detention are fulfilled.

\section{Mental disorder}

What is the category of mental disorder (mental illness, psychopathic disorder or mental impairment) in Section 3 or $37 / 41$ cases? What is the diagnosis (or provisional diagnosis in Section 2 cases)? It is helpful to provide focused and succinct evidence to support the diagnosis. The medical member will understand the necessary criteria for the diagnosis, but the tribunal needs to see or hear the evidence for this.

\section{Nature and degree}

'Nature' refers to the 'particular mental disorder . . . its chronicity, its prognosis and the patient's previous response to receiving treatment', and 'degree' to the 'current manifestation of the patient's disorder' ( $R \mathrm{v}$. Mental Health Review Tribunal for South Thames Region, ex parte Smith [1999]).

\section{Liability to detention}

You do not need to show that the patient needs to be detained in hospital, only that the patient should remain liable to detention (Section 72(1)(b)(i)). That is, the patient may be well enough to be on leave but it is necessary that he or she remains liable to recall to hospital or that the patient spends some time in hospital for treatment.

\section{Health or safety of the patient, or the protection of other persons}

You need to show that at least one of the above three criteria makes the patient's liability to detention justified (Section 2) or necessary (Section 3). 'Necessary' is a stronger criterion, indicating that that there is no reasonable alternative. You will need to provide support for your concerns about the patient's health, or safety or the protection of others, were the patient not liable to detention.

If the tribunal is not satisfied that the above criteria are met, then it 'shall direct the discharge of the patient'.

Questions from the solicitor may sometimes feel uncomfortable, but you have no reasons to be concerned if your case for the patient's continuing detention is clear. If your case is shaky, then you should consider whether you should discharge the patient.

\section{Questions by the RMO}

The tribunal will understand that you are a busy professional and is likely to be sympathetic to requests to be released after giving your evidence. Remember, however, that if you represent the responsible authority, you have a right to question witnesses. If you leave the hearing before the end you will miss hearing the rest of the evidence and will lose your chance to put things right by 
judicious questioning. It can be particularly useful to question the patient. You may think that the patient has presented surprisingly well and you may, therefore, wish to elicit some features of their mental state or attitudes to treatment. After the tribunal's questions and before the solicitor's final submission, the president may ask if you have any questions. If this does not happen, tactfully tell the president that you wish to ask questions.

\section{The tribunal's decision}

The tribunal announces its decision to the patient or his legal representative and to a representative of the hospital. It sends a written decision, giving the detailed reasons for its decision within a few days. Rarely, you may feel that the tribunal's decision is obviously - and perhaps dangerously - wrong. It is possible to challenge the decision by applying for judicial review and seeking a stay on the discharge of the patient. It would not be lawful, however, to immediately re-section a patient who you believe to have been wrongly discharged, 'in the absence of material circumstances of which the tribunal is not aware when it orders discharge' ( $R$ (on the application of H) [2002]).

'An ASW [approved social worker] may not lawfully apply for the admission of a patient whose discharge has been ordered by the decision of a mental health review tribunal of which the ASW is aware unless the ASW has formed the reasonable and bona fide opinion that he has information not known to the tribunal which puts a significantly different complexion on the case as compared with that which was before the tribunal' ( $R$ (on the application of von Brandenburg [2003])

\section{References}

$R$ (on the appliation of H) v. Mental Health ReviewTribunal North and East London Region and Secretary of State for Health (CA) [2001] 3 WLR 512.

$R$ (on the application of $H$ ) v. Ashworth Hospital Authority, R (on the application of Ashworth Hospital Authority) v. Mental Health ReviewTribunal for West Midlands and the North West Region [2002] EWCA Civ 923.

$R$ (on the application of Mersey Health Care NHS Trust) v. Mental Health Review Tribunal [2003] EWHC 1182 (Admin).

$R$ (on the application of von Brandenburg) $v$. East London and the City Mental Health NHS Trust [2003] UKHL 58.

R (on the application of S) v. Mental Health ReviewTribunal [2002] EWHC 2522 (Admin).

Rv. Mental Health ReviewTribunal for SouthThames Region, ex parte Smith [1999] C.O.D. 148, cited in JONES, R. (2002) Mental Health Act Manual (8th edn) at para 1056. London: Sweet \& Maxwell.

George J. Lodge Consultant Psychiatrist, Part-time Medical Member Mental Health ReviewTribunals, Bradford-on-Avon Health Centre, Station Approach, Bradford-on-Avon BA15 2AE 